\title{
RESENHA
}

\section{QUINHENTOS ANOS DE SOLIDÃO: ENSAIOS SOBRE AS DESIGUALDADES RACIAIS NO BRASIL}

\author{
Francine Rocha ${ }^{1}$
}

\section{Referência da obra resenhada:}

PAIXÃO, Marcelo. 500 anos de solidão: ensaios sobre as desigualdades raciais no Brasil. Curitiba: Appris, 2013. ${ }^{2}$

Se o Brasil não é um país racista, se nesse país vive-se uma democracia racial, como se explicaria que as condições de vida de negros e pardos muito pouco se alteraram positivamente mesmo nos momentos históricos mais favoráveis como os denominados de "milagre econômico"? Por que os afrodescendentes não desfrutam dos mesmos espaços sociais de representação e poder? Por que são essas as populações mais afetadas pelo homicídio de jovens e mortalidade materna e infantil evitável? Por que os negros pobres brasileiros vivem pior que os brancos pobres? São essas questões semoventes que permeiam as análises perpetradas pelo autor, economista pósgraduado em Sociologia e militante da causa da equidade racial no Brasil, mas também na América Latina.

Trata-se de uma coletânea publicada em 2013 integrada por alguns dos mais significativos trabalhos de reflexão realizados pelo autor entre os anos 2.004 e 2.012 sobre as desigualdades raciais no Brasil. Segundo o próprio, "não tenho como garantir que os artigos aqui compilados sejam necessariamente os mais importantes ou relevantes de toda minha produção nesse intervalo. Mas posso dizer que cada um deles foi escolhido [...] pelo tipo de agenda que incorporou, seja em termos de conteúdo, seja em termos que

\footnotetext{
${ }^{1}$ Psicóloga e Pedagoga; Doutoranda em Educação pela Universidade Federal do Paraná (UFPR), Linha: Cognição, aprendizagem e desenvolvimento. Mestra em Psicologia pela UFPR, Linha: Práticas educativas e produção de subjetividade. Técnica em Assuntos Educacionais no MEC e UFPR, Coordenadora da Assessoria a Projetos Educacionais e Comunicação (ASPEC) do Setor de Ciências Biológicas da UFPR. Endereço eletrônico: francine.rocha@ufpr.br.

2 Há que se registrar um erro de editoração no livro, cujo subtítulo em capa inicia por "estudos", entretanto na ficha catalográfica tal termo é substituído por "ensaios".
} 
metodologias apresentadas" (introdução à edição colombiana). Os capítulos não foram ordenados cronologicamente, mas pela temática.

A publicação decorre de um convite da pesquisadora Prof. Claudia Mosquera, da Universidade Nacional da Colômbia, interessada em publicar alguns dos estudos de Paixão naquele país. Em seguida, a editora Appris manifestou interesse em sua publicação no Brasil. Um dos artigos publicados na Colômbia, “Índice de Desenvolvimento Humano (IDH) dos grupos de cor ou raça no Brasil", foi substituído no Brasil (por outro no qual o autor faz "um diálogo crítico sobre a tradição desenvolvimentista acerca das relações raciais" (p. 20), em virtude de que aquele já havia constava de outra publicação do autor no Brasil: Desenvolvimento Humano e Relações Raciais (Ed. DP\&A, 2003). No livro há menção aos apoios da FordFoundation e do LAESER - Laboratório de Análises Econômicas, Históricas, Sociais e Estatísticas das Relações Raciais, vinculado à UFRJ, que foi fundado (2.006) e coordenado pelo autor, que também leciona no Instituto de Economia dessa Universidade.

Apesar de o título implicar uma temporalidade que remete aos anos de início da colonização das Américas e do Brasil, Paixão alerta para o fato de que não pretendeu proceder um resgate historiográfico, apesar de reconhecer a história das relações étnico-raciais como necessariamente subjacente à constituição desses interações. Em honra à Colômbia, anfitriã dessa sua obra, Paixão propõe o título do livro como homenagem ao país de origem do Nobel da Literatura (1.982) Gabriel García Márquez, o qual possui dentre seus mais famosos livros Cem anos de solidão". Não só por considerar que a significação da expressão do título remeta aos padrões relacionais estabelecidos nesses cinco séculos entre brancos, negros e indígenas, fortemente impregnados de violência, injustiça e exclusão, gerando a solidão nos alijados dos processos de controle e distribuição do poder e das riquezas, mas também pelo estilo de literatura "realista mágico" modelar apresentado em "Cem anos de solidão", constituído da fusão do universo irreal à realidade, dando a impressão do fantástico ser natural, habitual e corriqueiro. Dessa forma, prescindindo de explicação, perpetua-se o descalabro de se falar com mortos vivos (como em “Cem anos...") ou destituir de relevância a discussão sobre as implicações entre relações étnico-raciais e fortes disparidades nas condições de vida de brancos, 
RESENHA

QUINHENTOS ANOS DE SOLIDÂO: ENSAIOS SOBRE AS DESIGUALDADES RACIAIS NO BRASIL

negros, mestiços e indígenas decorrentes hierarquização racial da sociedade brasileira, conforme explicitam diversos dados.

A história apresenta-se recursivamente no desenrolar dos argumentos fundamentados em dados, especialmente os estatísticos, e em confronto com diversas teorias do "pensamento social brasileiro". Segundo o autor, os projetos de modernização das nações são perpassados por ideologias que constituem o caráter de um povo, sua relação com a "civilidade" subjaz às relações de poder vigentes. Para além de uma curiosidade etnográfica, o tema da constituição da nacionalidade reflete estratégias perpetradas pelos dominadores da elite em vista de seus interesses econômicos e políticos.

Mais do que propor uma vigilância epistemológica sobre supostamente esporádicos desvios racializantes (apaziguadores ou declaradamente eugênicos) das relações de subalternização produzidas, Paixão não poupa os discursos aparentemente mais democráticos, como os que propõem e sustentam o mito da democracia racial vigente no Brasil. Não se espere encontrar nos "500 anos de solidão..." um discurso obnubilante sobre quais cânones Paixão está incidindo. Iconoclasta, desfere golpes definitivos sobre os mais relevantes teóricos e correntes de pensamento social do século XX no Brasil.

Para além desse confronto teórico, são os dados estatísticos os substratos das argumentações, a contundência dos mesmos fala por si. Encontrar-se-á, portanto, em todo o trabalho, a realidade da desigualdade desenhada por tais dados. Em defesa da necessidade de se produzirem os dados estatísticos, por mais de uma vez (como nos Capítulos 1 e 2, páginas 30-31; 79), Paixão repercute: “Morning [...] apontou que no período moderno quatro vetores levaram à coleta ou à não coleta de decomposição étnico-racial no interior das pesquisas demográficas: i) contabilização dos contingentes étnicoraciais com finalidades de controle político desses grupos; ii) não inclusão dos grupos étnico-raciais em nome da integração nacional; iii) fortalecimento do discurso do hibridismo ou da mestiçagem no seio da população (nesse caso podendo levar tanto à inclusão quanto à exclusão do quesito) e; iv) contabilização com finalidades para adoção de estratégias antidiscriminatórias ou favoráveis à adoção de políticas de ações afirmativas". 
Considerando que, “quando presente, o quesito étnico-racial seja o campo sócio-antropológico por excelência no interior de um questionário aplicado em pesquisas demográficas (... e que) as variáveis étnicas e raciais são notadamente influenciadas pelos padrões de inter-relacionamento étnicoraciais existentes no interior de cada realidade local” (p. 28), no Capítulo 1 - “A variável cor ou raça nos recenseamentos demográficos brasileiros: história e estimação recente de assimetrias", é discutida a complexidade envolvida na definição da variável étnico-racial nos censos, bem como alguns resultados dos censos brasileiros no que tange à presença de assimetrias desfavorecedoras dos negros em relação aos brancos no Brasil. Os termos etnia e raça são problematizados e politizados como instrumentos de desinvisibilização de discursos e práticas racistas, nesse sentido "trata-se da recriação de uma perspectiva de pensamento sim racializada, porém visando a promoção de seu contrário, isto é, o combate ao racismo e suas consequências deletérias. Dito de outro modo, se é bem verdade que toda forma de pensamento racista possui uma fundamentação racializada, não necessariamente uma forma de pensamento racializada precisa necessariamente ser racista. Pelo contrário, o racialismo antirracista reconhece que a realidade das raças é antes social, política e cultural, geradora de dinâmicas sociais correspondentes que produzem iniquidades" (p. 35) As principais assimetrias de cor e raça são apresentadas e analisadas, como: evolução da população brasileira (incluindo esperança de vida e padrão de nupcialidade da população feminina, dentre outros) e indicadores socioeconômicos (distribuição de rendimentos, população abaixo da linha de indigência, IDH etc.). A conclusão coloca que "condição negra, ou afrodescendente, remete antes a uma condição de identidade social (mesmo que ... heteroatribuída) que biológica" (p. 70) e aponta que foram os indicadores levantados "que de forma simples e objetiva vieram sendo capazes de revelar o tamanho dos abismos que cercam as condições de vida dos distintos grupos de cor ou raça no Brasil. Com isso, alimentaram o debate sobre a urgência de políticas de ações afirmativas e de promoção da equidade social." (p. 71) Sem pretender que o modelo de levantamentos de dados do Brasil possa ser transposto por outros países latino-americanos, Paixão assinala que “importa é que os sistemas classificatórios sobre a variável étnico-racial tenham a capacidade de operar de acordo com as dinâmicas 
RESENHA

QUINHENTOS ANOS DE SOLIDÂO: ENSAIOS SOBRE AS DESIGUALDADES RACIAIS NO BRASIL

sociais de cada realidade nacional [...] visando a intervenção por parte do poder público no sentido da reversão das assimetrias" (p. 73).

O Capítulo 2 - "Realidades da diáspora: presença afrodescendente nas Américas segundo a rodada de Censos de 2000" apresenta um “mapeamento da história dos censos demográficos dos países do Hemisfério Americano contendo a variável étnico-racial afrodescendente ao longo dos séculos XIX e XX; [...] países que realizaram levantamentos censitários ou amostrais na Rodada do ano $2.000 ;[\ldots]$ terminologias de perguntas e respostas; [...] totais populacionais afrodescendentes nos países nos quais aquele tipo de decomposição foi realizado" (p. 79) Em relação ao século XIX, evidencia-se que foram poucas as contagens populacionais contendo os descritivos decompostos por grupos étnico-raciais e condição social (livre ou escrava): Uruguai, Peru, Argentina, Brasil e Cuba são os citados. No século XX houve uma tendência ao desaparecimento dessa variável dos Censos realizados, o que o autor atribuiu a "estratégias das elites locais de geração de um projeto de Estado-nação ideologicamente associado à europeização ou à mestiçagem (ou, lido de outra maneira, calcado no aprofundamento da, já comentada, invisibilidade dos grupos ameríndios e afrodescendentes)." (p. 81) Cabe a ressalva que nos levantamentos realizados, a referência aos povos indígenas acabou sendo mais facilmente apresentada que aos afrodescendentes. $\mathrm{O}$ autor conclui que a utilização dos termos não representa nada de trivial, ao contrário, reflete “concepções socioculturais e políticas, de profundas consequências, em torno do próprio significado de projeto de Estado-nação. Assim, [...] representam os próprios embates dos diferentes grupos historicamente discriminados no sentido do seu reconhecimento em múltiplos planos, bem como expressam a resistência dos setores dominantes na plena incorporação daquelas tantas demandas sociais" (p. 108).

No Capítulo 3 - "O justo combate: reflexões sobre relações raciais e desenvolvimento", o autor propõe uma discussão acerca da correlação entre desenvolvimento econômico e relações raciais, alertando para a pertinência dessa associação. Empreende tal feito tomando, por exemplo, duas das principais correntes de pensamento em economia: Neoclássica e Marxista, e a relação dessas com as teorizações advindas da antropologia (física e cultural), 
com destaque para Gilberto Freyre, apesar de existirem outros tantos a partilharem e fomentarem a ideologia do "mito da democracia racial brasileira". Destrinchando os meandros das implicações dessa mitologia para a configuração do ideário desenvolvimentista, Paixão critica o "pensamento social" consagrado como silente aos abismos entre as condições de vida entre os brasileiros, fruto de uma hierarquização racial da sociedade, uma vez que "as assimetrias (são) o preço que se paga pela paz. Assim, no interior desse ponto de vista, são as disparidades raciais que garantem a qualidade dos modos de interação entre brancos e negros no Brasil. Essa é a chave do entendimento da Lenda da modernidade encantada. Ou melhor, esse é o segredo do racismo à brasileira" (p. 134).

"Evolução das assimetrias de cor ou raça no mercado de trabalho metropolitano brasileiro durante a Era Lula (2003-2010)” é o título do Capítulo 4 e nele são discutidas as repercussões de ambientes macroeconômicos sobre políticas de promoção da igualdade racial. Concluiu-se que ocorreram melhorias nos indicadores de emprego/ocupação e afins no que tange às populações negras e pardas, contribuindo para a redução das desigualdades entre brancos e pretos e pardos. Entretanto, persistindo as assimetrias entre brancos e os demais grupos, indicando, segundo Paixão," que os vetores estruturais, sozinhos, sejam incapazes de produzir uma mudança mais substancial na realidade das profundas desigualdades de cor e raça que vieram se consolidando ao longo das gerações." (p. 178) Ele sugere uma combinação de medidas que poderiam tornar um modelo de crescimento mais equânime entre as raças.

O Capítulo 5 - "Desigualdade de cor e raça nos indicadores de mortalidade materna no Brasil: evidências empíricas recentes”, pretende estender o estudo das assimetrias de cor e raça aos indicadores de óbitos maternos no Brasil. Demonstra as dificuldades implicadas no estudo, em vista da subnotificação e precariedade dos dados, bem como a relevância desse indicador para a avaliação da saúde de uma sociedade. Refutadas por completa as razões de ordem biológicas, restam dentre as conclusões que há incidência desigual de fatores geradores de mortalidade materna em desfavor das negras e pardas em relação às brancas, o que deveria resultar num estabelecimento de 
RESENHA

QUINHENTOS ANOS DE SOLIDÂO: ENSAIOS SOBRE AS DESIGUALDADES RACIAIS NO BRASIL

metas de atenção à saúde materna, "igualmente diferenciadas para esses coletivos" (p. 241).

Para além das diversas divergências epistemológicas e ontológicas, há uma convergência entre os pontos de partida e chegada entre as teorias que compõem o Panteão Sociológico Brasileiro no que tange à implementação de políticas afirmativas destinadas aos afrodescendentes. Essa é a ideia defendida por Paixão no Capítulo 6 - "A Santa Aliança: Estudo sobre o consenso crítico às políticas de promoção da equidade racial no Brasil". Nele são analisados os seguintes discursos teóricos: liberal, democrático-racial, nacionalista, culturalista contemporâneo, funcionalista, marxista e geneticista, sendo destacados aspectos de convergência e divergência entre os mesmos e dentro de seus próprios arcabouços. Provocativamente, o autor decreta: "todas as diferenças teóricas contidas entre autores liberais, comunitaristas, funcionalistas, nacionalistas e marxistas não foram suficientemente fortes para fazerem cada um deles se desviarem da rota que, afinal de contas, acabou dando rigorosamente no mesmo lugar. No frigir dos ovos parece que tal convergência denota mesmo uma espécie de mútuo reconhecimento racial camuflado" (p. 273): uma "santa aliança" expressando a branquidade como forma de poder, via de consequência, posicionando-se contrariamente à implementação de políticas de caráter afirmativo em relação aos contingentes humanos subalternizados e dominados.

Fechando o livro com mais um argumento instigador, Paixão, no Capítulo 7, intitulado "Antropofagia e racismo: uma crítica ao modelo brasileiro de relações raciais", reporta-se ao movimento artístico do modernismo brasileiro e à sedução que o canibalismo enquanto expressão positiva da nacionalidade exerceu sobre a elite brasileira a partir de então. Nesse sentido, o povo brasileiro teria uma propensão ao assimilacionismo do estrangeiro e do exótico, a tal ponto de o ter feito de forma quase literal em relação aos povos indígenas e, mais recentemente, em relação aos negros. Naquele movimento artístico, a referência ao canibalismo praticado pelos Tupinambás enquanto ritual para apropriação de características valoráveis (força, coragem etc.) do inimigo devorado, foi valorizado enquanto possibilidade de incorporação das diferenças. O que o autor questiona, entretanto, é que, ao contrário dos 
Tupinambás, as elites estiveram e ainda estão - tendo em vista o aumento da mortalidade violenta de jovens negros praticada inclusive pelas forças estatais, bem como os índices de mortalidade materna dessa população, entre outros promovendo um verdadeiro banquete visando à extinção dos afrodescendentes, tendo por meta o branqueamento da sociedade brasileira, necessário a que o mito da europeização da nação se processe e o grau de desenvolvimento econômico se viabilize. Enfim, uma teoria social estarrecedoramente cimentada nos dados estatísticos apresentados no livro.

Somente o debruçar-se sobre o livro poderá impregnar o leitor dessa sensibilização que avança muito em relação às sensibilizações provenientes do senso comum. Somente Paixão pode problematizar a função da cordialidade, do silêncio e da invisibilização de conflitos latentes na manutenção da transformação de uma diferença em desigualdade. Denúncia e anúncio, tratase de uma leitura indispensável para se conhecer o racismo à brasileira, bem como a pertinência de ações afirmativas raciais! 